AperTO - Archivio Istituzionale Open Access dell'Università di Torino

\title{
Arsenic mobility in natural and synthetic coprecipitation products
}

\section{This is the author's manuscript}

Original Citation:

Availability:

This version is available http://hdl.handle.net/2318/1661556

since 2018-03-07T13:12:18Z

Terms of use:

Open Access

Anyone can freely access the full text of works made available as "Open Access". Works made available under a Creative Commons license can be used according to the terms and conditions of said license. Use of all other works requires consent of the right holder (author or publisher) if not exempted from copyright protection by the applicable law. 


\title{
Arsenic mobility in natural and synthetic coprecipitation products
}

\author{
M. Martin, R. Balint, R. Gorra, L. Celi, E. Barberis \\ University of Torino, Italy
}

\author{
A. Violante \\ University of Napoli Federico II, Italy
}

SUMMARY: The release of As from coprecipitation products naturally formed in Bangladesh groundwaters was compared with that from synthetic Fe-As precipitates. Iron oxy(hydr)oxides were the main component of all materials, but the natural coprecpitates also contained carbonates, phosphates and microbial organic matter. Synthetic coprecipitation products released more As than the natural ones with several diluted extractants. Kinetics of As release from synthetic Fe-As coprecipitates evidenced a hindrance in As mobilization when a coverage of Ca-polygalacturonate was introduced. Hence, the organic interface could be a key factor in affecting the stability of such systems.

\section{SECTION 1. INTRODUCTION}

The introduction of As in the food chain largely depends on its mobility in the soil-water system. Sorption/desorption reactions mostly control As mobility in oxic environments, while under alternating redox conditions, such as in aquifers or temporarily flooded soils, precipitation/dissolution reactions may play a major role. These transformations can involve both abiotic and microbially-mediated reactions, resulting in rather variable, complex products, whose nature and stability, still not fully understood, depend on the environmental conditions, type and activity of the microbial communities. The parallel study of natural systems and in-vitro simplified models was aimed at understanding the role of different components of the complex systems forming in nature and the mechanisms involved in As mobility.

\section{SECTION 2. METHODS/EXPERIMENTAL}

\subsection{Sampling of natural coprecipitation products}

Arsenic-enriched coprecipitation products naturally formed were collected from different groundwater storage systems in Bangladesh. They were analyzed for chemical and mineralogical composition, stability and potential release of As under different conditions, and composition of the biofilm-forming microbial communities.

\subsection{Synthesis of coprecipitation products}

Synthetic $\mathrm{Fe}-\mathrm{As}(\mathrm{III})$ coprecipitation products were prepared at different As/Fe ratios. Part of each sample was immediately freeze-dried, part was aged for one year. All the samples were characterized for chemical and physical properties, mineralogy, potential As release under different conditions, as the natural products. The influence of a Capolygalacturonate network (Ca-PGA) on As release kinetics from the synthetic coprecipitation products was also evaluated by extractions with inorganic (Pi) and organic phosphate (IHP) solutions.

\section{SECTION 3. RESULTS AND DISCUSSION}

\subsection{Characterization of natural coprecipitation products}

The natural coprecipitates were heterogeneous materials, mainly consisting of amorphous and poorlycrystalline phases, containing 30-40\% Fe (w/w), 5$10 \% \mathrm{Ca}, 2.5-6 \% \mathrm{P}, 2.5-4 \%$ organic $\mathrm{C}(2-4 \%)$ and inorganic $\mathrm{C}(1-4 \%)$. Arsenic $(0.2-0.5 \%)$ was present in both tri- and pentavalent forms, diffusely distributed within the amorphous matrix. The crystalline phases consisted of calcite, $\mathrm{Ca}$ - and Fe-phosphates. The complex distribution of $\mathrm{P}, \mathrm{As}, \mathrm{Fe}$ and $\mathrm{Ca}$ within the coprecipitate components suggested the adsorption of $\mathrm{P}$ and As on the iron oxides surfaces, but did not exclude the possible nucleation of $\mathrm{Ca} / \mathrm{Fe}$ arsenophosphates. The organic matter was mostly from microbial origin. The microbial community contained methylotrophic Betaproteobacteria, Gallionella-like iron oxidizers, methanogens, methylotrophs, and sulphate reducers while no phylotypes known to be directly involved in As(V) respiration or As(III) oxidation were found (Gorra et al., 2012).

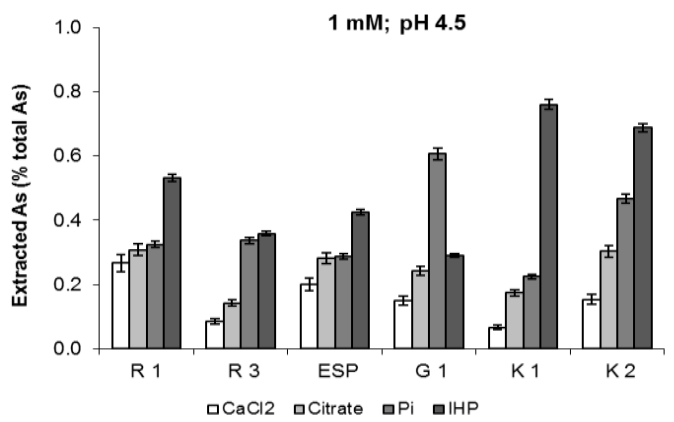

Figure 1: Percentage of total As extracted with $1 \mathrm{mM} \mathrm{CaCl}$, citrate, inorganic phosphate (Pi), inositol hexaphosphate (IHP) from the natural coprecipitation products. 
The crystallinity of these coprecipitation products did not increase with ageing. The extractability of As with different anions potentially occurring in soils and waters was moderate (Fig.1). Inositol phosphate was often the best As extractant, particularly when the organic matter was low, probably because of its competition with As for adsorption as well as for its Fe-complexing ability (Celi et al., 2003).

\subsection{Characterization of synthetic coprecipitation products}

The synthetic As/Fe coprecipitation products were poorly crystalline and their specific surface area increased with As content. After one year of ageing some goethite formed in the 0.005 and $0.010 \mathrm{As} / \mathrm{Fe}$ molar ratio products, while the 0.050 one remained poorly crystalline (Violante et al., 2007). The proportion of extractable As increased with As saturation (Fig. 2) and, differently from the natural coprecipitates, Pi always extracted more As than IHP. This was attributed to the microporous structure of the materials, hampering the large organic molecules to access the surfaces (Celi et al., 2003).

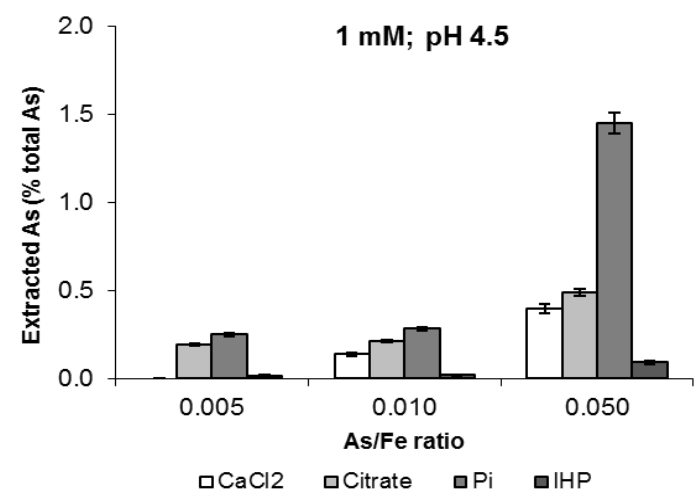

Figure 2: Percentage of total As extracted with $1 \mathrm{mM} \mathrm{CaCl}$, citrate, inorganic phosphate (Pi), inositol hexaphosphate (IHP) from synthetic coprecipitation products.

The ageing of the coprecipitation products often resulted in an increased As release, attributed to the crystallization process inducing a decrease in the specific surface area.

\subsection{Subsection 3.3}

When the coprecipitation products were embedded in a Ca-polygalacturonate network, the release of As with both inorganic P (fig. 3) and IHP (not shown) was slower, probably because of the diffusion of the solutes was hampered by the organic network. The presence of the PGA network was even more effective in preventing As release when the larger IHP molecule was involved (not shown).

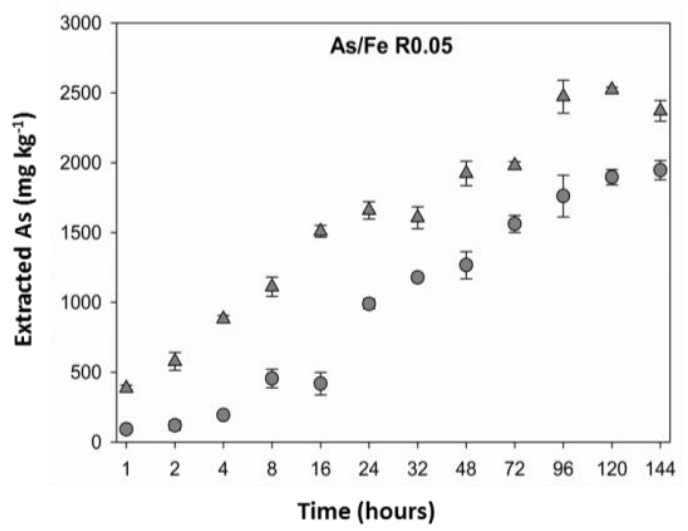

Figure 3: Kinetic of As extraction with inorganic phosphate from uncovered (triangles) or Ca-PGA covered (circles) cprecipitation product with $0.05 \mathrm{As} / \mathrm{Fe}$ molar ratio.

\section{SECTION 4. CONCLUSIONS}

The natural coprecipitation products were complex materials, formed in anoxic/oxic niches supporting a phylogenetically and metabolically diverse group of biofilm-forming prokariotes. Although these materials remained in poorly crystalline form, hence potentially highly reactive, their potential As release into the environment was probably limited also by the presence of microbial organic matter embedding the mineral phases. The synthetic, pure As/Fe coprecipitates released more As than the natural ones when treated with diluted extractants. The inclusion of the synthetic coprecipitation products within a Capolygalacturonate network resulted in a slower and overall scarcer As release, approaching the behavior obtained with the naturally formed ones.

\section{ACKNOWLEDGEMENTS}

This study was funded by the Italian Ministry of University and Research (MIUR), PRIN Project 2010-11.

\section{REFERENCES}

Celi L, De Luca G, Barberis E. 2003. Effects of interaction of organic and inorganic $\mathrm{P}$ with ferrihydrite and kaolinite-iron oxide systems on iron release. Soil Science 168: 479-488.

Gorra R., Webster G., Martin M., Celi L., Mapelli F., Weightman A. 2012. Dynamic microbial community associated with iron-arsenic co-precipitation products from a growndwater storage system in Bangladesh. Microbial Ecology, 64: $171-186$

Violante A, Gaudio SD, Pigna M, Ricciardella M, Banerjee D. 2007. Coprecipitation of arsenate with metal oxides. 2. Nature, mineralogy, and reactivity of iron(III) precipitates. Environmental Science \& Technology 41: 8275-8280. 